\title{
Journey to the Center of the Core: Computers and the Internet in the Core Curriculum
}

\author{
Jorge Pérez and Meg Murray \\ Kennesaw State University, Kennesaw, Georgia, USA
}

\author{
jperez@kennesaw.edu mcmurray@kennesaw.edu
}

\begin{abstract}
Computers, digitalization and the Internet have transformed modern society. Commerce, education, communication and socialization will never be the same. Surprisingly, many universities do not require a computing course in the core curriculum. Critical information technology (IT) competencies are often taken for granted, to the detriment of students who lack computing and Internet skills. This paper describes an initiative undertaken by a computer science and information systems department to assess and remediate IT skills needed by all university students, regardless of major. The project is evolving along several dimensions: identification of disciplineindependent IT competencies, assessment of IT skills among current and incoming students, and curriculum development.
\end{abstract}

Keywords: assessment, curriculum, education, computer skills, information systems, computer science, Internet.

\section{Introduction}

No industry is untouched by the information technology revolution. Commerce, education, communication and socialization are among the areas that are undergoing radical transformations. At most universities, fundamental IT skills have not risen to the level of must-have competencies such as math and English. Surprisingly, many universities do not assess IT skills or require a computing course in the core curriculum. Critical IT competencies are often taken for granted, to the detriment of students who lack computing and Internet skills.

Not too many years ago, requiring students to demonstrate a basic level of computer competency was an issue on many college campuses. Several institutions developed computer literacy courses that all students were required to take. The primary focus of these courses was developing basic skills in the use of applications such as word processing, spreadsheet and presentation software. Eventually, these computer skill-based courses began to disappear as many educators believed

Material published as part of this publication, either on-line or in print, is copyrighted by the Informing Science Institute. Permission to make digital or paper copy of part or all of these works for personal or classroom use is granted without fee provided that the copies are not made or distributed for profit or commercial advantage AND that copies 1) bear this notice in full and 2) give the full citation on the first page. It is permissible to abstract these works so long as credit is given. To copy in all other cases or to republish or to post on a server or to redistribute to lists requires specific permission and payment of a fee. Contact Publisher@InformingScience.org to request redistribution permission. that students were entering the university well-versed in basic computer usage.

While most students today have exposure to computers and experience using the Internet, a gap is emerging between functional and analytical uses of computing technologies. Students may be able to word process and surf the Internet, but they often do not understand the fundamentals of how and why these 
technologies work. An analogy is often put forth that relates using a computer to driving a car. Certainly, one does not need to know the engineering principles or mechanical processes that make an automobile work to be a successful driver. But the comparison of the automobile to the computer is incomplete. Whereas the results of driving a car are distinct and finite, the outcomes of using the resources and information that emanate from computer technologies are infinite and complex. Cars get us from point A to point B; information technology allows us to reinterpret the journey.

We have entered the age of ubiquitous and pervasive computing. Universities are again pondering what defines computer literacy and what specific skills are needed to effectively utilize computer technologies. Computer literacy has traditionally been defined as the ability to use computers to perform a variety of tasks, but that definition is no longer adequate. Computer literacy no longer simply means viewing a computer as a collection of applications; it also means using the computer as a means of communication and a source of information (Hoffman, Blake, McKeon, Leone, \& Schorr, 2005). These same authors provide an expanded definition of computer literacy. Specifically, they state that computer literacy includes both "information literacy, the ability to evaluate information found online, and critical computer literacy, the ability to incorporate computing technology in support of critical thinking” (p. 164). Moreover, computer literacy must now be extended to digital literacy, as students are increasingly expected to interact with information and content made omnipresent by the fact that it is digitized and available on a cadre of devices.

The challenge of redefining a core course in computing lies in operationalizing the expanded definition of computer literacy. This is a major undertaking as the functional definition of computer literacy is expansive. This paper describes an initiative undertaken by two computer science and information systems professors to assess and remediate IT skills needed by all students at one regional university, regardless of major. The project is evolving along three dimensions: identification of discipline-independent IT competencies, assessment of IT skills among current and incoming students, and curriculum development. Each dimension is elaborated upon below.

\section{Identifying IT Competencies}

\section{Preliminary Research}

A preliminary investigation was undertaken to formulate a framework upon which a special topics course offering could be developed. The first phase of this investigation involved reviewing current literature and related course offerings in the areas of computer literacy and information literacy, as well as engaging in introspection with experienced faculty members. This investigation resulted in the identification of a set of exploratory questions that serve as the basis for identifying critical IT competencies that should be included in a computing course offered as part of a core curriculum. The set of questions include:

- What computing skills should any incoming college student possess?

- What should students know about purchasing a computer or upgrading an existing system?

- What does a college student need to know to effectively use a computer as a problemsolving tool?

- What should any student know about using the Internet for research and assessing the reputability of Internet sources?

- What should a college graduate know about computers and the Internet to succeed in any chosen profession? 
- What do computer and Internet users need to know about ethics, privacy, security, globalization and diversity?

- What does one need to know about digital photography, music and video to enrich one's life with these technologies?

An exploratory survey of junior and senior IS majors in a required capstone course showed that a majority viewed familiarity with the Internet and World Wide Web as among the most important IT skills. Also rated as highly important was the ability to use applications such as Word, PowerPoint, Excel and Access, in that order.

\section{Focus Group}

The next phase of the preliminary investigation was to share the exploratory questions with interested stakeholders for the purpose of facilitating more in-depth discussions. Two primary groups of stakeholders were identified. These included faculty who teach in the computer science and information systems department and industry professionals who serve on the department's Industry Advisory Board. Approximately 20 faculty and 12 industry experts participated in the focus group discussion. Several general observations and specific suggestions arose from the focus group. First, the focus group perceived that many college students have only superficial IT skills. One participant remarked that while it was once enough for students to be casual computer users, they now need to become power users. Another focus group member mentioned that universities should prepare students for life-long learning about IT.

In the area of computer usage, the group identified the need for students to understand the "total cost of ownership" of computing devices. Specifically, students should engage in an exercise of specifying the configuration of a computer that meets their specific needs. Then they need to develop a maintenance plan for software and operating system updates, as well as a security plan that addresses protection from viruses, spyware and intrusions on privacy.

Related to information literacy, the group felt that students need to learn to manage information overload by developing skills in searching, applying filters and data reduction techniques. Specifically, they identified that students need to be able make sense of the vast amount of information available online. Moreover, students should be able to make critical value judgments about the sources of any specific information that they access online.

Another area that was explored was the need to understand and assess student perceptions of how computing impacts their lives and how confident they feel in their interactions with information technologies. Computing technologies are becoming more pervasive, not only in school and work related applications, but also as mediums for social interactions. Consequently, it is important for universities to identify and assess critical IT competencies and provide opportunities for students to remediate these IT skills.

Finally, the focus group identified the need for students to engage in conversations about ethical issues in computing and the Internet. Students need to be aware of matters related to privacy and security, and understand basic concepts about intellectual property, copyright and standards of ethical use.

\section{Symposium}

The authors have organized a symposium at an upcoming annual conference on university teaching. The symposium will cultivate a dialogue with colleagues across disciplines and institutions. Another objective of the symposium is to move the discussion of IT skills to the high school level, where remediation of math and English skills is well established, but assessment of IT 
competencies is not. Panelists in the symposium include the authors, a professor of communications, and a teacher at a private high school.

\section{Future Directions for Identifying IT Competencies}

The authors are developing a number of survey instruments. Questionnaires will be administered to high school and university students, educators and administrators. In addition, IT practitioners and recruiters for general, non-IT positions will also be surveyed. The intent of the surveys is to continue to refine the findings of the previous stages in which core IT skills were identified. The authors will also proceed with exploration of the IT skills addressed in the curricula of high schools and universities.

\section{Assessment of IT Competencies}

For quite some time, institutions of higher education have espoused the need to create graduates who demonstrate a set of IT competencies. While there is no standard set of computer skills that clearly define the IT competent individual, many institutions have implemented assessment measures that attempt to ascertain the specific computer skills students possess. For the most part, these assessments focus on basic computer operations, use of functional software such as word processors and basic skills in searching the Internet and using e-mail. A typical computer literacy assessment instrument evaluates student skill levels in such tasks as creating a document in a word processor, naming the parts of a computer, sending an e-mail, participating in a chat session and using a search engine on the WWW. Some instruments even include sections related to creating a Web page and setting up a small network.

Perhaps one of the best examples of a widely available computer literacy assessment instrument for undergraduate students is known as the Tek.Xam. Tek.Xam is a partnership between the Virginia Foundation for Independent Colleges, and ACT, Inc, an internationally known educational assessment corporation. Tek.Xam tests student proficiency in seven areas, including General Computing, Knowledge and Use of the Internet, Word Processing, Spreadsheets, Presentations, Databases and Web Authorship. Another widely available assessment instrument is sponsored by the International Computer Driving License (ICDL) (http://www2.icdlus.com/icdlus-lmswebclient/), an international essential IT skills certification in use by over 50 countries. The ICDL assesses skills in the areas of basic IT concepts, operating environments, word processing, spreadsheets, databases, presentation graphics and the Internet and e-mail. Each of these instruments assesses needed and worthwhile IT skills, but they represent only one aspect of computer literacy. They focus on the functional use of computers; they do not attempt to evaluate the analytical skills students need to be able to use computing technologies to support critical thinking activities.

George Mason University instituted a “Technology Across the Curriculum” program that has received national and international recognition. The purpose of the program is "to promote the most effective uses of technology to enhance learning” (George Mason University, 2005). As part of this program, they have identified ten IT skills and knowledge areas that are most important for liberal arts students. The knowledge areas attempt to expand upon functional computer based literacy to include outcomes of computer use. For instance, the goals are stated in terms such as "Students are expected to be able to use information technology for data presentation and communication, for data organization and search, and for data analysis. In addition, students are expected to possess a basic understanding of legal and ethical issues related to IT and of basic computing concepts” (Holisky, n.d.).

In the area of critical computer literacy skills, the Association of American Colleges and Universities has identified the importance of technology in higher education (Ehmann, 2004). Specifi- 
cally, they identify five key educational outcomes of a liberal education and how computing technologies are necessary to support the attainment of these objectives. Their outcomes focus on the development of strong analytical skills, inquiry practices through hands-on experiences, developing intercultural knowledge and collaborative problem-solving skills, developing civic responsibility through the connection of knowledge, skills, values and action, and fostering integrative thinking and the ability to transfer skills and knowledge. For each of these areas they suggest activities that can be used to facilitate the attainment of student outcomes, and they suggest the use of an online portfolio as an assessment instrument. The focus is away from teaching functional computer usage skills towards integrating the use of technology as a means to achieve critical computer literacy.

What has become apparent when considering what constitutes a core course in computer literacy is that the notion cannot be defined from simply a functional or a critical perspective. Obviously, one cannot be a critical computer user without having functional usage skills. On the other hand, simply being able to master basic computer functions is not enough to describe one as computer literate. A course focused on meeting the needs of today's students in the area of critical IT competencies must, therefore, provide a bridge between these two extremes.

\section{Imparting IT Competencies: Curriculum Development}

Based upon the preliminary investigations and research on assessments, a special topics course was developed. The purpose of the course is to address IT competencies identified as critical to the success of any university student. However, it should be noted that the development of this course is an iterative process. The course will be subjected to an extensive evaluation process. In addition, the authors are developing a number of survey instruments that will be administered to high school and university students, educators and administrators. Moreover, IT practitioners and recruiters for general, non-IT positions will also be surveyed. The intent of the surveys and the course evaluation is to incorporate the findings into the development of the curriculum for a course that facilitates student development of critical IT competencies.

In order to synthesize the findings of the initial investigations, guiding principles for the evolution of the course were defined. These principles help to categorize the many competency areas and skills sets previously identified. The basic premise of the guiding principles recognizes that many of the students who participate in such a course will be college freshmen who have at least casual experience as computer and Internet users. The goal is to empower students with the skills necessary so that they can effectively use these technologies to support critical thinking activities.

\section{Guiding Principles:}

- Know Yourself

o Know your strengths and limitations as a computer and Internet user

- Inform Yourself

o Be resourceful and know where to locate useful, relevant information

o Manage your learning about computers and the Internet

- Protect Yourself

o Protect your identity on the Internet

o Know who knows what about you

o Protect your computer and network from common attacks 
- Express Yourself

o Communicate what you know about computers and the Internet

o Share and present ideas using the Internet and common computer applications

- Enjoy Yourself

o Have fun with digital music, photography and video

o Participate in blogs, vlogs and other virtual communities

- Empower Yourself

o Be confident in what you know and can learn about computers and the Internet

\section{Course Objectives}

Drawing from the guiding principles, general learning objectives were articulated and are outlined below.

Students who complete the course will (be able to):

- become a well-rounded, confident user of PCs and the Internet.

- use PC applications to solve common problems encountered at home, school or work.

- protect a networked PC from various security and privacy threats.

- conduct research on the Internet, assessing reputability of Internet sources.

- be aware of the social impacts of computers and the Internet.

- articulate a position on ethical issues regarding computers and the Internet.

\section{Specific Learning Modules}

The course content is under development and refinement. At the time of this writing, the specific course modules are as follows:

1. General computing and hardware

a. Configure a PC desktop or notebook system for purchase

b. How to purchase computers and PC components

c. Replace or install components such as RAM modules, hard drives, CD-ROMs and expansion cards

2. Operating system and applications

a. Set up a logical file folder structure

b. Manage files and encrypt sensitive data

c. Control panel functions and administrative tools in Windows

d. Search for files on a PC system

e. Solve a real-world problem using common applications such as spreadsheet, database, presentation and word processing software

f. Communicate and present ideas using common PC applications

3. Recovery 
a. Reinstall an operating system to a reformatted hard drive

b. Create and boot from a bootable floppy or CD

c. Back up documents and data to CD-R, USB key, or other media

4. Internet and networking

a. Recognize the difference between scholarly sources and news, practitioner publications, and un-edited articles that are available via the Internet

b. Know what constitutes plagiarism and how to avoid it

c. Find a computer's MAC address and IP address

d. Set up a wireless router, including WEP and MAC filter

e. Use PING, TRACERT and IPCONFIG at the command prompt

f. Use FTP to upload files to a Web server

g. Cookie settings to achieve an acceptable balance between privacy and utility

h. Protect against spyware, viruses and exploits

i. Create and upload a basic web site (e-portfolio)

5. Music, photography and video

a. Uses of the JPG and GIF file formats

b. Edit a photograph and attach a photo to an e-mail message

c. Using MP3 and other audio compression options

d. Common video formats

e. Streaming audio and video

f. Legal issues regarding copyrights and file sharing

6. Domain-specific knowledge - What you should know about how computers and the Internet are used in diverse fields:
a. Business
b. Psychology
c. Biology
d. Education
e. Nursing
f. Others

\section{Course Description}

With the general objectives and specific learning modules in mind, the course description was developed:

Start | Run | Learn. Computers and the Internet have revolutionized society. Every profession is affected. Communication, education and commerce have been transformed. Music, films, photography and books are digitized. Students who enroll in this course will rip a music CD, edit and email a digital photograph, reinstall an operating system, design a database, conduct research on 
the web, secure a wireless router, participate in an online community and create a web site. Issues explored include security, privacy, globalization, diversity and ethics. Be a well-rounded user of computers and the Internet. Don't get left behind by the information technology revolution.

\section{Conclusion}

There is a well-established history of assessment and remediation of math and English skills at all levels of education. This paper argues that the age of pervasive computing dictates that core IT competencies rise to the level of math and English as universal skills that are evaluated, imparted and nurtured by all institutions of higher education. The iterative three-dimensional program designed by the authors of the paper flows from identification of critical IT competencies, to assessment, to remediation via curriculum development. The program is iterative because whereas basic math remains basic math, new computing applications are introduced at an accelerating pace.

There is a continuum of institutional approaches toward assessment and delivery of IT competencies. Some institutions, such as George Mason University, have developed extensive programs to infuse IT competencies throughout the curriculum. Other institutions have at least one IT course that is a requirement for all students. The university at which the authors teach does not require an IT course in its core curriculum, but encourages students to take free computing workshops that are sponsored by the institution's IT department. Basic, intermediate and advanced workshops are offered in popular word processing, spreadsheet, and presentation applications, and students may also take a workshop in which they learn how to create a basic Web page. Self-remediation works for some students but might leave others behind. At the other extreme, one can imagine that at least some institutions are grappling with how to establish and deliver a baseline of core IT competencies.

The program described in this paper is in its early stages. The course outlined above will be offered for the first time in an upcoming term. In the short run, assessments will be conducted, the course content will be refined, and additional conduits will be sought by which to establish multidisciplinary dialogues across the university. More focus groups are planned and other assessments will be designed. Administrators and educators will be surveyed to ascertain levels of awareness and agreement on the university's role in delivering IT competencies. The long-term objective is to shrink yet another digital divide - the often pronounced gaps that exist between the most and least technologically savvy of our students.

\section{References}

Bartholomew, K. C. (2004 October). Computer literacy: Is the emperor still exposed after all these years? Journal of Computing Sciences in Colleges, 20(1), 323-331.

Ehmann, S. (2004). Beyond computer literacy: Implications of technology for the content of a college education. Liberal Education. Retrieved November 30, 2005, from http://www.aacuedu.org/liberaleducation/le-fa04/le-fa04feature1.cfm

George Mason University. (2005). Technology across the curriculum. Retrieved November 30, 2005, from http://cas.gmu.edu/tac/index.html

Hoffman, M. \& Blake, J. (2003 May). Computer literacy: Today and tomorrow. Journal of Computing Sciences in Colleges, 18(5), 221 - 233.

Hoffman, M., Blake, J., McKeon, J., Leone, S. \& Schorr, M. (2005 May). A critical computer literacy course. Journal of Computing Sciences in Colleges, 20(5), 163-175.

Holisky, D. A. (n.d.). Ten IT goals: Information technology goals for liberal arts students. George Mason University. Retrieved November 30, 2005, from http://cas.gmu.edu/tac/goals/tenitgoals.html 
Harvey, B. (1983). Stop saying “Computer Literacy”! Retrieved November 30, 2005, from http://www.cs.berkeley.edu/ bh/stop.html

Tek.Xam. (2005). Retrieved November 30, 2005, from http://www.tekxam.com

\section{Biographies}

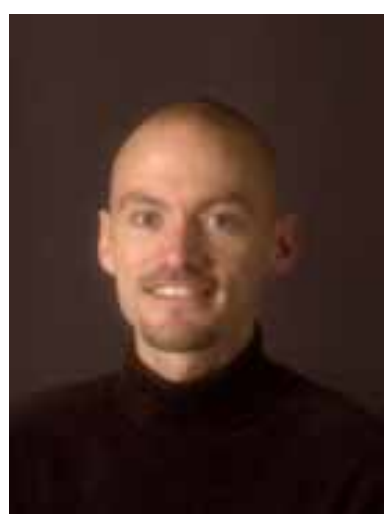

Jorge Pérez is an Assistant Professor in the Computer Science and Information Systems Department at Kennesaw State University. He holds a Ph.D. in Information Systems and has over nineteen years of experience in the field as a consultant, systems analyst, web developer and educator. Professor Pérez teaches e-business, web development and informatics at the undergraduate and graduate levels. He has published and presented research on information security, diffusion of innovations, and organizational learning. His current research focuses on identifying, assessing and imparting competencies that are needed by any informed user of information technology and the Internet.

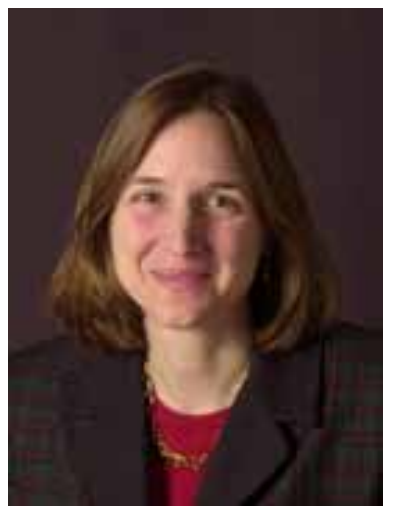

Meg Murray is an Associate Professor in the Department of Computer Science and Information Systems at Kennesaw State University, part of the higher education system of the state of Georgia. She holds a $\mathrm{PhD}$ in Information Systems, an MBA in Finance and a MS in Computer Science. She has been in the field of computing for more than twenty years and has served both in higher education and industry. Dr. Murray specializes in the area of emerging technologies and the development and implementation of those technologies to meet business and organizational needs with a special interest in technology infusion in healthcare. Her current work has been in the area of Web services, including exploring the supporting technologies of XML, SOAP, .Net and J2EE, and she has been an author and presenter on the technical and societal implications of the evolving software paradigm referred to as 'Software as a Service.' Her focus in teaching is to inspire students to create and devise new and innovative ways to implement information technologies to solve real-world problems. Her most recent work is in the area of devising strategies to assess and remediate IT skills needed by an educated workforce to ensure they are able to use the power of technology as a means for innovation * the driver necessary to sustain economic growth in the state and in the country. 